
World Ecology

\title{
Ecoregions and ecosystem management in China
}

\author{
Bo-Jie Fu , Guo-Hua Liu , Yi-He Lü , Li-Ding Chen \& Ke-Ming Ma
}

To cite this article: Bo-Jie Fu , Guo-Hua Liu , Yi-He Lü , Li-Ding Chen \& Ke-Ming Ma (2004) Ecoregions and ecosystem management in China, International Journal of Sustainable Development \& World Ecology, 11:4, 397-409, DOI: 10.1080/13504500409469842

To link to this article: http://dx.doi.org/10.1080/13504500409469842

\section{曲 Published online: 02 Jun 2009.}

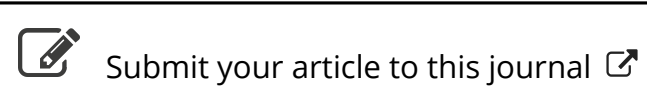

Џll Article views: 60

Q View related articles $\sqsubset$

Citing articles: 1 View citing articles ๘ 


\title{
Ecoregions and ecosystem management in China
}

\author{
Bo-Jie Fu, Guo-Hua Liu, Yi-He Lü, Li-Ding Chen and Ke-Ming Ma \\ Key Laboratory Systems Ecology, Research Center Eco-Environmental Sciences, Chinese \\ Academy of Sciences, P.O. Box 2871, Beijing 100085, China
}

Key words: Ecoregion, classification level, ecosystem management, China

\begin{abstract}
SUMMARY
Ecological regionalization is a base for rational management and sustainable utilization of ecosystems and natural resources. It can provide a scientific basis for constructing healthy ecological environments and making policies of environmental management. In this paper, based on synthetic analysis of the characteristics of the ecology and environments of China, the principles of ecological regionalization are discussed, and indices and nomenclature of ecological regionalization are proposed. The ecoregions on a national scale are divided. The results show that there are 3 domains, 13 ecoregions and 57 ecodistricts. The present scheme can be used as a framework for ecosystem assessment and management. Based on the ecoregions, measurements of management for forest, grassland, agriculture and wetland ecosystems are recommended. The experience and information can be used within and beyond the national scale for landuse planning, biodiversity conservation and ecosystem restoration.
\end{abstract}

\section{INTRODUCTION}

With the development of global and regional economies and the intensification of human activities, natural ecosystems are subjected to more and more human intervention. The problems of ecological and environmental degradation, at various scales, plague the further improvement of society and the economy. Ecological regionalization is a powerful tool and a sound basis for identification and tackling of the related problems (Omernik 1995). The interaction between man and ecosystems is an important research field in modern ecology. Ecological regionalization and mapping of many countries have been given much importance in recent years (Bailey 1998; Wiken $e t$ al. 1996; Hardin and Winterbourn 1997). However, because of the diverse natural environmental conditions and characteristics of human intervention, the contents of ecological regionalization in different countries are very distinctive. Ecological regionalization such as most of that in the North American region often refers to the regionalization of natural ecosystems (Bailey 1983, 1989; Omernik 1987; Wiken et al. 1996).

In its most basic form, ecological regionalization involves discriminating between different spatial patterns or associations of site-specific ecosystems (Bailey 1985). Based on intensive study and deep understanding of ecosystems, the present paper manages to uncover the rules underlying the similarity and differentiation of natural ecoregions and human intervention in ecosystems, and then suggest ecological

Correspondence: Bo-Jie Fu, Research Center for Eco-Environmental Sciences, Chinese Academy of Sciences, P.O. Box 2871, Beijing 100085, China. e-mail: bfu@mail.rcees.ac.cn 
regionalization through bottom-up integration and top-down division ( $\mathrm{Liu}$ and $\mathrm{Fu}$ 1998). Although progressed on the basis of various physical regionalizations, ecological regionalization is quite different. It considers not only the process and characteristics of natural ecosystems, but also the effects of human activity. In this respect, it is the unification of characteristic and functional regionalization (Liu and Fu 1998; Fu et al. 1999).

According to different objects and intentions of regionalization, the distinctiveness of ecological regionalization is evident. Different requirements can be raised for the different social and eco-environmental status during different periods of their evolution. Consequently, ecological regionalization should improve with the development of social economy and the deepening insights for nature (Fu et al. 1999). To put the ecosystem (biotic and abiotic environments) as the object at the macro-scale, with indepth research of the characteristics and rules about factors such as ecoregions, ecosystem services, ecological capital, ecological vulnerability and the threats to eco-environment from humankind in China, the paper presents principles, methods and indices for ecological regionalization at the national level. On the basis of this regionalization, the ecoregions in China are divided and combined within different hierarchical ecological units. The purpose of the present study is to identify the ecological and environmental problems and their mechanisms of formation, to support the policy-making process for rational exploitation, utilization and environmental conservation, and to serve for the rehabilitation and restoration of ecosystems and environments. It is a pathway and framework for sustainable development.

\section{METHODS}

\section{Principles}

The role of ecological regionalization is to reflect the true differentiation rules of various regional units objectively and completely. Accordingly, it is necessary to know the process of construction, structural and functional characteristics, and spatial distribution of ecosystems as well as other factors concerned. Therefore, the fundamental principles for ecological regionalization depend on its object and the understanding of that object. It is well known that the present ecosystems are the results of comprehensive interactions between long-term processes of natural evolution and human disturbance. With unique structures, functions and characteristics, different ecosystems that undergo human impacts of different intensity occupy various geographical spatial locations (Fu et al. 2004). Generally, ecosystems have the following characteristics: similarity and dissimilarity; a hierarchy; intensity of human disturbance; etc. The integration and classification of various ecosystems must be done correctly to form ecoregions in terms of these characteristics. Thus, it is crucial to abide by the following principles during the course of ecological regionalization:

(1) The differentiation of ecoregions: The integral macro-ecosystem is composed of a series of different types of ecosystems which distribute continuously in space. Because of the differences of climate, physiognomy, geomorphology and soil conditions within different regions, there are differentiations between and within different regions. According to these differentiations, ecoregions of different level are defined and recognized. Thus it can be seen that the differentiation of ecoregions is the theoretical foundation of ecological regionalization and also a very basic principle

(2) The hierarchy of ecosystems: Hierarchy theory, which includes the structural hierarchy of ecosystems and the hierarchy of ecological processes, is the keystone for a better understanding of the spatial patterns of ecosystems. In general, the characteristics of ecosystem hierarchy can be characterized as follows (Klijn and de Haes 1994): (a) The patterns of higher level components can be represented in the lower level hierarchy; (b) Lower level components depend on higher levels for existence; (c) Materials and energy usually flow from a higher level to a lower level; (d) The change of some individual components affects the related components inevitably. It is obvious that the 
hierarchy principle is the theoretical base to recognize and define ecoregions step by step across various scales. Therefore, ecoregions should be hierarchical, with their size depending on the scale of study, and their boundaries based on semipermanent landscape components (Bailey et al. 1994).

(3) The similarity and dissimilarity within and between ecoregions. The physical geographical environment is the concrete background within which ecosystems undergo succession, differentiation and evolution. Although the eco-environment within an ecoregion tends to be homogeneous, the structure of ecosystems within the region also shows some similarity and dissimilarity on account of some other differences of physical factors.

Based on these, ecoregions are identified and generalized, and then incorporated and divided at different scales in the course of ecological regionalization.

Additionally, ecosystems are more or less disturbed by human beings but the intensity of disturbances may differentiate between regions resulting in different status and problems for the eco-environment concerned. Hence, the anthropogenic factors have to be taken into account to give a rational view of the implications of humans for the evolution of ecosystems and environments.

\section{Indices system}

An indices system is the theoretical and operational tool to carry out the ecological regionalization. The system can be distinctive according to different objects, scales, purposes and researchers. So it is a very complex process to ascertain the system and is the topic that has aroused much debate in the history of research. However, for whatever the regionalization, the indices chosen and the entire system of indices decided for use have to represent the purpose of the work and the regional differentiation for as long as possible. The structure, function and process of evolution, which is controlled and affected by many factors and their interactions, are extremely complex. Therefore, it is necessary to give a comprehensive analysis of the indices to grasp dominant factors. Generally, atmospheric processes are the main determinants of ecosystems at large spatial scales, and thermal moisture distribution is mainly affected by topography and geomorphology. Thus, the climatic and geomorphologic factors are often used as part of the main indices during the process of ecological regionalization (Klijn and de Haes 1994; Harding and Winterbourn 1997).

We have three levels of classification to derive the ecological regionalization scheme. According to the characteristics of climate, topography, geomorphology, ecosystems and anthropogenic features in China, we choose qualitative and quantitative indices for different levels of classification.

\section{Level I}

China lies to the west of the Pacific Ocean. The climate in China is influenced mainly by the East Asia monsoon. The ladder-like relief, with three steps, in China plays an important role in modifying the climate, making the dominant features of the climate in China humid in the east, arid in the west and extremely cold on the plateau of Tibet. The types of macro-ecosystems, such as forests, grasslands, deserts and meadows under cold climate, are controlled by thermal moisture factors. So, based mainly on the features of the climate and relief in China, we use two types of indices to make the first level classification: (a) thermal moisture and climatic indices, including dryness or aridity (annual rainfall and evapotranspiration), humidity and mean annual temperature; (b) the differentiation of relief, including large-scale patterns of relief and elevation. We then define the main ecological zones, such as the humid ecological domain, arid ecological domain and extremely cold ecological domain. Within each domain, we select further indices to make the second level classification.

\section{Level II}

This level is closely related to the patterns of landform and geomorphology and the climatic conditions at large scales. The patterns of land- 
form and geomorphology continue to affect the distribution of thermal moisture factors at large scales within the framework of the first level. For example, thermal factors are related to latitude and moisture is related to longitude. Furthermore, these factors result in further differentiation of the ecosystem types within the first level regions. This can be reflected by the general rules that zonal vegetations distribute along latitude and longitude. So that, for the second level, we use the following two types of indices: (a) indices of temperature and moisture including mean annual temperature, $\geq 10^{\circ} \mathrm{C}$ accumulated temperature and annual rainfall; (b) zonal vegetation types, including the latitudinal and longitudinal differentiation of the vegetation types. Here, zonal vegetations are the main indices for division, with the regional differentiation of other indices taken into full consideration.

\section{Level III}

The regions of this level should belong to types of the same geomorphological origin. The third level geomorphological types are subdivisions comparing features of geomorphology. Within second level regions, the geomorphological types lead to further differentiation of the ecosystem types. Different geomorphological types have distinctive environmental factors that make the structure and species composition of ecosystems, ecosystem services, susceptibility and vulnerability of ecosystems differ in some degree. In addition, the complexity and characteristics of human activities are mainly represented at this level. On the one hand, the population pressure and the demand for land resources, as well as irrational use of the resources, largely affect natural ecosystems, and even devastate them with severe environmental problems such as soil erosion and desertification aroused. On the other hand, through scientific management practices and moderate disturbance, people can construct artificial ecosystems with high productivity to serve development of humankind. Therefore, the ecosystems within the same region of the third level are supposed to have similar species composition, structure, ecosystem service, ecological susceptibility and vulnerability, as well as characteristics of human activities. In this case, the following three types of indices should be taken into account for the third level division: (a) geomorphological types including basin, plain, river valley, plateau and hill; (b) types of ecosystems including the structure and species composition of ecosystems, ecosystem services and ecological susceptibility; (c) indices concerning human activities including population density, land use, soil erosion and desertification.

\section{Nomenclature}

The nomenclature of the ecological regions, which is the direct representation of the hierarchy of ecological regions, is an important step of the ecological regionalization. We classify the ecological regions in China to three levels, namely the first level 'Domain', the second level 'Ecoregion' and the third level 'Ecodistrict'. At each level, the nomenclature of the ecological regions mainly follows: (a) to characterize each region exactly; (b) to indicate the geographical location of the regions; (c) to make clear the ecosystem types; (d) the 'tiles' of the ecological regions at the same level should correspond to each other; (e) to represent the effects of humans towards the eco-environment; (f) to be literally concise and readily accepted. Thus we consider mainly the factors of Domain (geographical location and thermal moisture condition), Ecoregion (thermal moisture condition and typical zonal vegetation types), Ecodistrict (geomorphological types and ecosystem types and human activities).

\section{ECOREGIONS OF CHINA}

Based on the above methods with the regional features of physical environment, ecosystem types, main regional environmental problems and status of human activities in China, we use the holistic approach which is a combination of top-down classification processes, expert integration and quantitative modelling (Yang and $\mathrm{Li}$ 1999) to carry out the present scheme of ecological regionalization. First, the Level I classification is mainly based upon the features of climate formed under the influence of the East Asia monsoon and the corresponding difference of ecosystem types. At the same time, we follow 


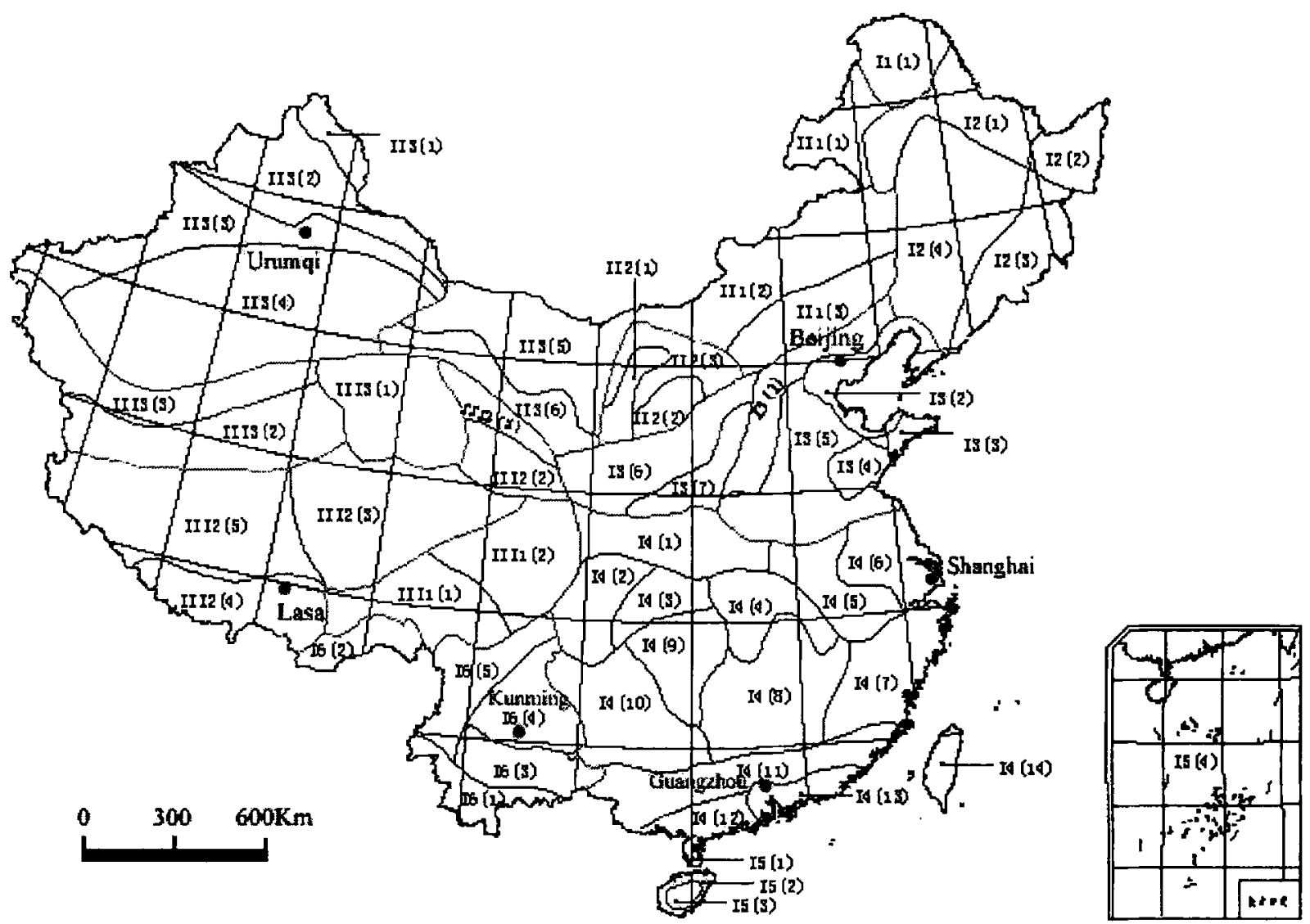

Figure 1 Ecological regionalization map of China

the traditional division scheme of three main large-scale regions, given the consideration of previous studies and their acceptability. Consequently, we have three domains at the Level I: eastern humid and semi-humid domain, northwestern arid and semi-arid domain, and the extremely cold domain of the Tibet plateau. We then divide this into 13 ecoregions at Level II (6 in the east, 4 in the west and 3 in the Tibet plateau), and at Level III these are subdivided into 57 ecodistricts ( 35 in the east, 12 in the west and 10 in the Tibet plateau, see Figure 1).

I Eastern humid and semi-humid domain

$I_{1} \quad$ Humid coniferous forest ecoregion of cold temperate zone

$I_{1(1)} \quad$ Northern Daxinganling mountain coniferous forest ecodistrict

$I_{2}$ Humid needle broadleaved mixed forest ecoregion of the temperate zone

$\mathrm{I}_{2(1)}$ Daxinganling and Xiaoxinganling mountain needle broadleaved mixed forest ecodistrict

$I_{2(2)}$ Sanjiang Plain agriculture and wetland ecodistrict

$I_{2(3)} \quad$ Changbaishan Mountain needle broadleaved mixed forest ecodistrict

$I_{2(4)} \quad$ Northeastern Plain agriculture ecodistrict

I 3 Humid and semi-humid deciduous broadleaved forest ecoregion of warm temperate zone

$\mathbf{I}_{3(1)}$ Deciduous broadleaved forest ecodistrict of North China mountain region

$\mathbf{I}_{3(2)} \quad$ Urban and suburban agriculture ecodistrict circles Bohai Bay region

$\mathrm{I}_{3(3)}$ Deciduous broadleaved forest ecodistrict of Liaodong Peninsular

$I_{3(4)}$ Deciduous broadleaved forest ecodistrict of middle southern Shandong hilly mountain region

$I_{3(5)} \quad$ Huanghuaihai Plain agriculture ecodistrict

$I_{3(6)}$ The ecodistrict vulnerable to soil erosion in the Loess Plateau 
$I_{3(7)} \quad$ Fenhe and Weihe River valley agriculture ecodistrict

$\mathrm{I}_{4}$ Humid evergreen broadleaved forest ecoregion of the sub-tropical zone

$\mathrm{I}_{4(1)} \quad$ Evergreen-deciduous broadleaved forest ecodistrict of Qin-Ba Mountains region

$\mathrm{I}_{4(2)} \quad$ Chengdu Plain agriculture ecodistrict

$I_{4(3)}$ Vulnerable ecodistrict of the Three Gorges Reservoir region

$\mathrm{I}_{4(4)} \quad$ Mainstream Yangtze River plain agriculture and wetland ecodistrict

$\mathrm{I}_{4(5)}$ Dabieshan and Tianmushan Mountain evergreen broadleaved forest ecodistrict

$I_{4(6)} \quad$ Yangtze River delta urban and suburban agriculture ecodistrict

$I_{4(7)} \quad$ Zhejiang-Fujian Mountains evergreen broadleaved forest ecodistrict

$\mathrm{I}_{4(8)} \quad$ Hunan-Jiangxi Hills agriculture ecodistrict

$\mathrm{I}_{4(9)}$ Western Hunan and Eastern Guizhou Mountains evergreen broadleaved forest ecodistrict

$I_{4(10)}$ Guangxi-Guizhou Karst vulnerable ecodistrict

$I_{4(11)} \quad$ Lingnan Mountain evergreen broadleaved forest ecodistrict

$\mathrm{I}_{4(12)}$ Southwest Guangdong coastal hill agriculture ecodistrict

$\mathrm{I}_{4(13)}$ Zhujiang River delta urban and suburban agriculture ecodistrict

$\mathbf{I}_{4(14)}$ Taiwan Island evergreen broadleaved forest ecodistrict

$I_{5}$ Humid rain forest monsoon forest ecoregion of the tropical zone

$I_{5(1)} \quad$ Leizhou Peninsular tropical agriculture ecodistrict

$I_{5(2)} \quad$ Circle Hainan Island tropical agriculture ecodistrict

$I_{5(3)}$ Middle Hainan Island mountain rain forest monsoon forest ecodistrict

$\mathrm{I}_{5(4)} \quad$ South China Sea islands ecodistrict

$I_{6}$ Humid and semi-humid evergreen broadleaved forest ecoregion of South Asia monsoon zone

$I_{6(1)} \quad$ Xishuangbanna tropical rain forest monsoon forest ecodistrict

$\mathrm{I}_{6(2)}$ East Himalaya Mountains tropical rain forest monsoon forest ecodistrict

$I_{6(3)}$ South Yun-Gui Plateau humid evergreen broadleaved forest ecodistrict

$I_{6(4)} \quad$ North Yun-Gui Plateau semi-humid evergreen broadleaved forest ecodistrict

$I_{6(5)}$ Hengduanshan Mountain evergreen broadleaved forest and shady coniferous forest ecodistrict

II Northwest arid and semi-arid domain

$\mathrm{II}_{1}$ Semi-arid prairie ecoregion

$\mathrm{II}_{1(1)}$ Hulunbeier prairie ecodistrict

$\mathrm{II}_{1(2)}$ Inner Mongolia Plateau arid ecodistrict

$\mathrm{II}_{1(3)}$ Southeast Inner Mongolia Plateau agriculture grazing ecotone vulnerable ecodistrict

$\mathrm{II}_{2}$ Semi-arid desert prairie ecoregion

$\mathrm{II}_{2(1)}$ Hetao alluvial plain irrigated agriculture ecodistrict

$\mathrm{II}_{2(2)} \quad \mathrm{Mu}$ Us Desert ecodistrict

$\mathrm{II}_{2(3)}$ Eerduosi Plateau desert prairie ecodistrict

$\mathrm{II}_{3} \quad$ Arid and semi-desert ecoregion

II $_{3(1)}$ Arasan Plateau semi-desert ecodistrict

$\mathrm{II}_{3(2)}$ Hexi Corridor oasis agriculture ecodistrict

$\mathrm{II}_{4} \quad$ Arid desert ecoregion

$\mathrm{II}_{4(1)}$ Aertai Mountain forest prairie ecodistrict

$\mathrm{II}_{4(2)}$ Zhungaer Basin desert ecodistrict

$\mathrm{II}_{4(3)}$ Tianshan Mountain prairie coniferous forest ecodistrict

$\mathrm{II}_{4(4)}$ Talimu Basin desert Gobi ecodistrict

III Tibet Plateau extremely cold domain

$\mathrm{III}_{1}$ Tibet Plateau forest and extremely cold meadow ecoregion

$\mathrm{III}_{1(1)}$ Southeast Tibet Plateau evergreen broadleaved forest and shady coniferous forest ecodistrict

III $_{1(2)}$ East Tibet Plateau shady coniferous forest and extremely cold meadow ecodistrict 
$\mathrm{III}_{2}$ Tibet Plateau alpine prairie and extremely cold meadow ecoregion III $_{2(1)}$ Qilianshan Mountain coniferous forest and extremely cold meadow ecodistrict III $_{2(2)}$ East Qinghai agriculture grazing ecodistrict

$\mathrm{III}_{2(3)}$ Riverhead region extremely cold meadow ecodistrict

III $_{2(4)}$ South Tibet agriculture grazing ecodistrict

$\mathrm{III}_{2(5)}$ Qiangtang Plateau extremely cold prairie ecodistrict

$\mathrm{III}_{3}$ Tibet Plateau extremely cold desert and semi-desert ecoregion

III $_{3(1)}$ Qaidam Basin desert and salt desert ecodistrict

III $_{3(2)}$ Hoh Xil Desert and semi-desert ecodistrict

III $_{3(3)}$ Kara-Kunlun Mountain gravel desert ecodistrict

\section{IMPLICATIONS FOR ECOSYSTEMS MANAGEMENT}

From the era of the Industrial Revolution, human beings have seized all sorts of resources from nature for developing their social economy, with no end and no order. This has caused many bad consequences, such as natural resource decrease, biodiversity loss, land degradation, destroyed environment. These consequences threaten humankind's survival and development. Therefore, ecological security has increasingly caused many scientists and governments concerns. Indeed, it is important for national security. Thus, many scientists began to rethink the ideas and knowledge of ecosystem management (Aley et al. 1998; UNDP 2000). Today, the goals of ecosystem management are very different from the traditional ones. They mainly focus on ecosystem functions for environment protection, and not only on ecosystem production. They also emphasize the sustainable use of natural resources. Because the natural conditions are very different, ecosystem management is faced with many difficulties at national or regional scales. Ecoregions are thought of as a framework or a tool for ecosystem management (Omernik 1995; CECC 1997; Wright et al. 1998).

\section{Forest ecosystem management}

Forest is a main type of global terrestrial ecosystem. It plays vital roles for maintaining our global environment and social development, such as carbon sequestration, soil protection, biodiversity, climate regulation and wood product supply. However, we are faced with the fact that the global forests are decreasing dramatically, and that many environmental problems are caused by destruction of forest. Indeed, the history of human development is a history of forest destruction. And now, mankind is cognizant of the forest's significance, not only for wood products, but also for environment protection.

China is one of the countries with the lowest forest coverage in the world. The area of forest in China is about 133.70 million hectares (not including Taiwan, Hong Kong and Macao), making up $13.9 \%$ of the whole Chinese territory (Ministry of Forestry 1994; The Editorial Board of Forest in China 1997). The distribution of Chinese forests is in disequilibrium. Because they are influenced by the natural conditions, Chinese forests are mainly located in the eastern region. In the northwest only a few forests are scattered in mountains such as Tianshan Mountain, Aertai Mountain, Qilian Mountain. In our ecoregion scheme, there are 23 ecodistricts that have forest ecosystems. In recent years, the forest area has been expanded dramatically due to the establishment of timber plantations, shelterbelts and by natural forest protection. However, there are also many problems in Chinese forests (Liu et al. 2000a):

(1) Forest fragmentation: In China, because of the growing population and long agricultural history, most forestlands have been turned into farmlands. Thus, current forests are extremely fragmented, especially in Eastern China. Most forests are isolated and only distributed on some mountains and hills, forming many 'forest islands'. It is well known that only when a piece of forest reaches a certain area, can it fulfil its functions for environment protection and wildlife habitat. Forest fragmentation maybe enhances the frangibility of Chinese forest. 
(2) Poor quality of forest: In China, secondary forest is the principal type. The area of natural forest is only $\mathbf{8 7 . 2 6}$ million hectares, about $65.3 \%$ of the total forest area and $9 \%$ of the territory area. The areas of open forest and shrub forest are 18.02 million hectares and one million hectares, respectively (Ministry of Forestry 1989). This indicates that Chinese forest quality is very poor. Compared to the $1980 \mathrm{~s}$, Chinese forest increased by 9.5 million hectares in the early 1990s (Ministry of Forestry 1989). However, this increase is mainly focused on the increased areas of open forest, manmade forest and shrub forest. The area of natural forests is decreasing, especially the area of natural mature forest which has decreased by 7.32 million hectares compared to the end of the 1970s (Ministry of Forestry 1983).

(3) Simple ecosystem structure of forest stands: China has the largest area of afforestation. For meeting the high demand for wood products, fast-growing tree species such as Chinese fir, Masoon pine and poplar were chosen. The area of established plantations totals 34.25 million hectares in China, and accounts for $\mathbf{2 6 . 6 5 \%}$ of the total forested land area (Shi et al. 1998). These manmade forests always have a simple structure (e.g only one tree species). Consequently, the stability of such forests is low. When disturbed by external forces (e.g. forest fire, diseases and pests), they are very easily destroyed. It is incontestable that manmade forests play some roles for alleviating and ameliorating our environments (e.g. forest shelterbelts in Three Northern region), however, their ecological service functions are far lower than that of natural forests.

(4) Immoderate age structure of forest stands: Young and middle age forests forms a large proportion of Chinese forests which has increased from $63.8 \%$ in 1976 to $81.5 \%$ in 1993 (Liu et al. 2000b). This immoderate age structure indicates that Chinese forests are young and cannot meet the demands for timber for a long time. This shortcoming also shows that Chinese forest is not stable.

(5) Low productivity of forest stands: The average stem volume of Chinese forest is $83 \mathrm{~m}^{3} \cdot \mathrm{hm}^{-2}$, only three-quarter of that of the global average $\left(110 \mathrm{~m}^{3} \cdot \mathrm{hm}^{-2}\right)$. The Chinese forest average biomass is $77.4 \mathrm{t} \cdot \mathrm{hm}^{-2}$ (Liu et al. $2000 \mathrm{~b}$ ), only $45 \%$ of that global average (according to Dixon et al. (1994), the global forest average biomass is $172 \mathrm{t} \cdot \mathrm{hm}^{2}$ ).

The reasons that have led to these problems are mainly inadequate forest management, unsound systems in the government forestry sector, and policy mistakes. During the past several decades, there have been many organizations in the forest sector, such as bureaus of forestry in central and local government, national forest enterprises, collective forestry, and individual forestry companies. However, the authorities are very uncoordinated. Many organizations only emphasized economic benefits, and largely neglected planning for timber logging. The phenomena of indiscriminate logging and illegal poaching are extremely serious, as a result, many bureaus in the national forest region have essentially run out of timber resources (Yin 1998). For example, in Western Sichuan, the forest coverage has decreased from more than $30 \%$ in the 1950 s to less than $20 \%$ in the early 1990 s. Correspondingly, the area of water and soil erosion in the Yangtze River basin has increased from 36 million hectares in the 1950 s to 56.2 million hectares at the end of the 1980s (Mao and Li 1994).

Although there are many problems, it is not denied that the Chinese government has made great efforts to resolve them in the past decade, and also makes much progress with forest development. Some important documents for forest development and environment protection, such as the Implementation Plan for Forest Principles, the Forestry Action Plan for China's Agenda 21, Outline of China's Programme for Environment Development, and China Biodiversity Conservation Action Plan were formulated. In 1998, a project of natural forest protection that forbids timber logging all over the country began. The ten long-term planned projects for forest development and environment protection have ultimately been implemented 
(Shi et al. 1998): the Three-North Shelterbelt Project, the upper and mid-Yangtze River Basin Shelterbelt Project, the Coastal Shelterbelt Project, the Plain Afforestation Project, the Taihang Mountains Afforestation Project, the Shelterbelt Project for Comprehensive Management of Huaihe River and Taihu Lake Basin Area, the Pearl River Valley Shelterbelt Project, the Liaohe River Valley Integrated Shelterbelt Project, the Shelter Project along the Middle Reaches of the Yellow River, and the Natural Forest Protection Project. Furthermore, about 14.6 million hectares of natural reserves that related to forest for providing wildlife habitats had been established by the end of 1995 (according to SEPAC and EBCRRCB 1998). In 2000, another huge project called 'grain for green' was proposed and began to be implemented. Because these shelterbelt projects were established, the environments in some fragile areas had been ameliorated.

With social economic development, some new strategies must be adopted for sustainable development of forest resources. There are many detailed discussions about the reform of forestry sectors, forestry policies and forestry ownership rights (Yin 1998; Shi et al. 1998). However, few papers talk about the appropriate practices of forest ecosystem management. As pointed out above, Chinese forests are mainly distributed in 23 ecodistricts. In different ecodistricts, there are distinct forest ecosystems, natural conditions, and human activities. Furthermore, the different forest ecosystems also have different structures and functions, and are operated by different ecological processes and mechanisms. Thus, the measures of forest ecosystem management must correspond to different regions and types.

\section{Grassland ecosystem management}

In China, the area of grassland is about 263.52 million hectares (not including Taiwan, Hong Kong and Macao), making up $27.5 \%$ of the total area. Grasslands are mainly located on the Inner Mongolia Plateau, Xinjiang, and Tibetan Plateau. There are 5 ecodistricts relative to grassland in our ecoregion scheme.

Because of rigorous natural conditions (such as aridity and poor soil quality), they make up the second largest ecotone in the world, from the Inner Mongolia Plateau to the Xinjiang Municipality. Land desertification is the main environmental problem. Desertification is caused by both natural factors (e.g. climate) and inappropriate human activities (including overgrazing, cultivation, excessive gathering of fuelwood, and excavating plant species for medicinal purposes). As inner factors, natural conditions determine that these regions are prone to suffer desertification, and human activities, as exterior forces, play a role for accelerating desertification. In these regions, the social economy is very underdeveloped and poverty and lag are the main regional social problems. With the fast expansion of population in recent decades, people feed large number of cattle or reclaim grassland for cultivated land in pursuit of economic benefits for survival. This has caused overgrazing and grassland areas have decreased sharply, leading to serious desertification and poor quality of grassland.

At present, the area of desertification in China is about 160.7 million hectares, accounting for $16.7 \%$ of the total country area. About 136.8 million hectares of desertification lands are distributed in arid and semi-arid regions, making up 53.3\% of these regions' total area (CCICCD 1997). In the early 1990s, the degraded grasslands were about 84.2 million hectares in the arid and semi-arid regions, accounting for about $60 \%$ of the total grasslands in these regions (CCICCD 1997). These regions have become the origin of Northern China's sand storms that have moved nearer to Beijing (Zhu and Zhu 1999).

Since the 1950s, enormous efforts have gone into combating desertification in China. Especially from 1978, when the Three-North Shelterbelt Project was started, 5.68 million hectares of manmade forests have been built. By the end of the 1990 s, about $12 \%$ desertification lands had been improved, and about $10 \%$ desertification lands had been controlled in the Three-North region. However, the situation of desertification is still grave for the whole country. From the 1950s to the 1970s, the annual rate of desertification was 156000 ha (Zhu 1985), reaching 210000 ha in the 1980s (Zhu and Chen 1994). In the 1990s, it reached 246000 ha (CCICCD 1997).

Recently, the efforts for combating desertification were enhanced. Many projects have been implemented, such as the National Project of Combating Desertification, the National Eco- 
Environmental Construction Planning, and the Project for Returning Farmland to Grassland. Some new technologies have also been applied to monitor the changes in desertification (Sun and Zhou 2000). Furthermore, some techniques and models for combating desertification and degraded grassland ecosystems rehabilitation have been summarized according to the past practices (Zha and Gao 1997; Zhu and Zhu 1999; Lu 2000).

Many measures of grassland ecosystem management have been adopted according to the different conditions in different ecodistrics. First, most herdsman have changed their traditional custom of nomadism and now have adopted enclosure grazing. In some seriously degraded regions, herdsmen are forbidden to graze. Second, the amount of cattle is controlled according to the carrying capacity in a region. Third, the pastures have been improved by introducing some high quality herbaceous species. Fourth, the area of manmade pasture has been increased. Fifth, industries related to grazing have been increasingly developed.

\section{Agricultural ecosystem management}

It is well known that the cultivated land is the base for people's food supply. In China, there are 125.93 million hectares of cultivated land and 10.79 million hectares of horticultural land (Ministry of Land and Resources 2003). As one of largest agricultural countries in the world, farmers in China account for $80 \%$ of its population, nearly $22 \%$ of the world's population, but the Chinese rely on only $7 \%$ of the world's land resources (Liu and Fu 2000). This is a heavy burden. Now, with the development of the social economy and expansion of population, there are many problems that must be faced in Chinese agriculture:

(1) Cultivated land reduction: Although China is the third biggest country, there are only about 0.11 ha land per capita, only one third of the world average. In the past 15 years, about 5.4 million hectares of cultivated land have been lost, nearly 360000 ha of cultivated land per annum, corresponding to a loss of the ability to grow 2.5 billion kilograms of grain per year (EPRCC 1997). By 2002, the reduction in cultivated lands was about 1.66 million hectares, compared to that in 2001 . However, this is mainly because of returning cultivated lands to forestlands and grasslands (Ministry of Land and Resources 2003).

(2) Soil erosion: Soil erosion is one of the main problems in China. Because of the large population and a lack of arable land, many other areas (such as forestland, grassland, and wetland) must be continuously reclaimed to satisfy people's demands for sufficient food. Many arable lands are located in mountains and hills and easily suffer from water and soil erosion. At present, a common perception is that the areas of soil erosion, including water and wind erosion, are 3.67 million $\mathrm{km}^{2}$, about $38.2 \%$ of the territory. In some regions there is serious soil erosion. In the Loess Plateau, the soil erosion area is $450000 \mathrm{~km}^{2}$, up to $79 \%$ of the total area in this region, which loses about 1.6 billion tons of topsoil annually. In the Yangtze River Valley, the loss of topsoil is 2.24 billion tons per year (Mao and Li 1994).

(3) Degradation of land quality: Because of the increasing utilization of pesticides, herbicides and fertilizer, the physical and chemical properties of soils have been severely altered. Moreover, lots of waste water pours into the rivers and enters irrigation systems without any treatment. This results in cultivated lands being seriously polluted. Thus, the cultivated land quality is increasingly degraded. According to investigations, about $30 \%$ of cultivated land's production is very low, and about 6.67 million hectares of cultivated land are affected by pollution (Mao and $\operatorname{Li}$ 1994).

(4) Water resources shortage: In China, there are about 3540 billion $\mathrm{m}^{3}$ water resources. About $81 \%$ of water resources are located south of the Yangtze River, and large regions of northern China only have $19 \%$ of total water resources. However, there are large areas of cultivated lands in northern China that are extremely 
short of water resources, especially in Huanghuaihai Plain which has $18.1 \%$ of the whole country's cultivated lands, but only $2.8 \%$ of the total water resources.

To prevent the agricultural environment from further deterioration, the Chinese government has made numerous efforts to improve agricultural conditions, such as the project 'grain for green', the South-North Water Transfer Project, several shelterbelt projects, and maintaining the balance of total area of cultivated land. However, the balance of total area of cultivated land with the development and expansion of urban areas, actually implies that millions of hectares of fertile land are currently turned to townships, industrial and road construction land, while areas of barren and marginal land are reclaimed as the cultivated land. Therefore, the quantity of cultivated land appears to be maintained in balance, but the quality of cultivated land is actually decreased.

In attempting to resolve the conflicts between agricultural production and environmental degradation, $\mathrm{Ma}$ and $\mathrm{Li}$ (1987) advanced the theory of agro-ecological engineering. Its propose is to establish highly efficient and sustainable agro-ecosystems that utilize natural resources rationally and maintain ecological stability. This agro-ecological engineering (or ecological agriculture) has paid increasing attention to agricultural ecosystem management and land planning (Ye et al. 2002; Zhong 1999), and considered to be a way towards sustainable agriculture (Liu and Fu 2000).

\section{Wetland ecosystem management}

Wetland is a non-zonal ecosystem. As a special ecosystem, wetlands play vital roles for maintaining biodiversity, regulating floods, purifying water quality, providing water and energy resources. It is called the 'kidney of our globe' and is a very important type of terrestrial ecosystem.

In China, wetlands are mainly located in the Sanjiang Plain, the middle and downriver plain of the Yangtze River, and the Tibetan Plateau. Wetland ecosystems are also distributed in the Yellow River Delta, the Liaohe River Delta, and on the eastern coast. The area of wetland is 65.94 million hectares in China, about $10 \%$ of the world's wetlands. Among these wetlands, there are about 25.94 million hectares natural wetland, including 11.97 million hectares of bog, 9.1 million hectares of lakes and 2.17 million hectares of coastal wetland. Another $\mathbf{4 0}$ million hectares are manmade wetland, mainly rice paddy amounting to 38 million hectares, and making up $95 \%$ of manmade wetland and $57.6 \%$ of the total wetland (Bureau of National Forestry 2000). For the past decades, wetland has played important roles in providing products and wildlife habitats and regulating floods, however, because of irrational over-exploitation of wetland resources, wetland ecosystems have been severely endangered and degraded.

First, the area of wetland has decreased dramatically. During the past 50 years, millions of hectares of wetland were reclaimed as farmland, e.g. 786000 ha of farmland, and 5345000 ha of natural bog in the Sanjiang Plain in 1949 (Liu and $\mathrm{Ma}$ 2002). By 2000, farmland had increased up to 5240000 ha and the natural bog had decreased to 835000 ha (Li et al. 2002). In the middle and downriver plain of the Yangtze River about 1000 lakes disappeared due to reclamation. The area of Tongting Lake (the second biggest lake in China) decreased from 430000 ha in 1949 to 240000 ha by the end of the 1990 s, shrunk about $40 \%$ (Bureau of National Forestry 2000). The area of Poyang Lake (the biggest lake in China) decreased from 516000 ha in 1954 to 386000 ha in 1996 (Kong et al. 2001). About 2.19 million hectares of coast wetland, about $50 \%$ of the total area of coast wetland, were lost. The area of mangrove decreased from 50000 ha in the early 1950 s to 14000 ha by the end of the 1990 s, reduced by about $72 \%$ of the total area (Bureau of National Forestry 2000). Furthermore, sands poured into and filled up lakes and reservoirs due to water and soil erosion, decreasing the area and volume of the lake. The decrease in area has led to wetlands (especially lakes) losing some functions, such as flood regulation and habitat fragmentation.

Second, the pollution of wetlands is serious. With the development of industry and increased utilization of pesticides and fertilizers, large amounts of waste water pour into rivers and lakes without treatment, making the water quality of lakes worse. According to investigations, about two thirds of lakes in China are eutrophic and 
more than one third of rivers are polluted (Bureau of National Forestry 2000). The wetland biodiversity is decreased, such as in Honghu Lake where 50 species of fish have been lost, half of the total species number in 40 years. Moreover, there are about 50 species of waterfowl in danger. Therefore, it is exigent for protecting wetlands.

In recent decades, the Chinese government has paid increasing attention to wetland conservation and rehabilitation. Until now, about 262 natural protection areas have been established, about 16.6 million hectares, seven of these are internationally important wetlands in the Ramsar Convention. In 2000, the government drew up the Action Plan of Wetland Conservation containing short and long-term targets. Meanwhile, 39 preferential projects began to operate (Bureau of National Forestry 2000). In some seriously degraded regions (e.g. Dongting Lake region), farmland has been returned to wetland or lake. From 1998, the government also began to control and improve the environments of eutrophic lakes such as Chaohu Lake, Taihu Lake and Dianchi Lake, where some progress has been made.

\section{ACKNOWLEDGEMENTS}

This work was supported by the Key Project of KIP, Chinese Academy of Sciences (KZCX2-405), National Natural Sciences Foundation of China (NSFC 40321101) and the Key Project of the Ninth Five Year Plan for Resource and Environment, Chinese Academy of Sciences (KZ951B1-208).

\section{REFERENCES}

Aley J, Burch WR Jr, Conover B and Field D. (eds). Ecosystem management: Adaptive strategies for natural resources organizations in the 21st century. Philadelphia, USA: Taylor \& Francis; 1998

Bailey RG. Delineation of ecosystem regions. Environmental Management 1983;7(4):365-73

Bailey RG. Ecological regionalization in Canada and the United States. Geoforum 1985;16(3):265-75

Bailey RG. Explanatory supplement to Ecoregions map of the continents. Environmental Conservation $1989 ; 16(4): 307-10$

Bailey RG. Ecoregions: The ecosystem geography of the oceans and continents. New York: Springer-Verlag; 1998

Bailey RG, Jensen ME, Cleland MT and Bourgern PS. Design and use of ecological mapping units. In Jensen ME and Bourgeron PS (eds), Ecosystem Management: Principles and Applications, Vol. 1. US Forest Service General Tech. Rep. PNWGTR-318; 1994:95-106

Bureau of National Forestry. China Wetlands Conservation Action Plan. Beijing: China Forestry Publishing; 2000

Commission for Environmental Cooperation, Canada (CECC) . Ecological Regions of North America: Toward a Common Perspective. Quebec, Canada: Commission for Environmental Cooperation; 1997

CICCD. China Country Paper to Combat Desertification. Beijing: China Forestry Publishing; 1997

Dixon RK, Brown S, Houghton RA et al. Carbon pools and flux of global forest ecosystems. Science 1994; 263:185-90
EPRCC (Environment Protection and Resources Conservation Committee). China Resources. National People's Congress, China; 1997

Fu BJ, Chen LD and Liu GH. The objectives, tasks and characteristics of China ecological regionalization. Acta Ecologica Sinica 1999;19(5):591-5

Fu BJ, Liu GH, Wang XK and Ouyang ZY. The Ecological Issues and Risk Assessment in China. The International Journal of Sustainable Development and World Ecology 2004;11:143-9

Harding JS and Winterbourn MJ. An ecoregion classification of the South Island, New Zealand. Joumal of Environmental Management 1997;51:27587

Huang XW and Chen BM. The theory and application about the regionalization of Chinese ecological assets. Acta Ecologica Sinica 1999;19(5):602-06

Klijn F and de Haes HA. A hierarchical approach to ecosystems and its implication for ecological land classification. Landscape Ecology 1994;9(2):89-104

Kong P, Zhang XX, Jiang Y. Study on management of wetland in Poyang Lake. Environment $\mathcal{E}^{2}$ Exploitation $2001 ; 16(4) 41-4$

Kuchler AW. Problems in classifying and mapping vegetation for ecological regionalization. Ecology 1973;54:512-23

Li Y, Zhang YZ and Zhang SW. The landscape pattern and ecological effect of the marsh changes in the Sanjiang Plain. Scientia Geographica Sinica 2002; 22(6) 677-82

Liu XT and Ma XH. Natural Environment Changes and 
Ecological Protection in the Sanjiang Plain. Beijing, China: Science Press; 2002

Liu GH and Fu BJ. The principle and characteristics of Ecological regionalization. Advances in Environmental Sciences 1998;6(6):67-72

Liu GH, Fu BJ, Chen LD and Guo XD. Characteristics and distributions of degraded ecological type in China. Acta Ecologica Sinica 2000a;20(1):13-19

Liu GH, Fu BJ and Fang JY. Carbon dynamics of Chinese forests and its contribution to global carbon balance. Acta Ecologica Sinica 2000b;20(5):733-40

Liu GH, Fu BJ. Agro-ecological engineering in China: a way towards sustainable Agriculture. Journal of Environmental Sciences 2000;12(4):422-9

Lu Q (ed.). Desertification: Urgent Challenge China Faces. Beijing: Kaiming Press; 2000

Ma S and Li S. Agroecological engineering in China. Beijing: Science Press; 1987

Mao W and Li S. The Strategies of Sustainable Development in China. Beijing: China Science \& Technology Press; 1994

Ministry of Forestry, P.R. China. NationalForest Resource Statistics (1977-1981). Beijing; 1983

Ministry of Forestry, P.R. China. NationalForest Resource Statistics (1984-1988). Beijing; 1989

Ministry of Forestry, P.R. China. NationalForest Resource Statistics (1989-1994). Beijing; 1994

Ministry of Land and Resources, P.R. China. Communique of China's Lands and Resources in 2000. http://www.mlr.gov.cn/query/gtzygk; 2003

OmernikJM. Ecoregions of the conterminous United States. Annuals of the Association of American Geographers 1987;77(1):118-25

Omernik JM. Ecoregions: A framework for managing ecosystems. The George WrightForum 1995;12(1):3550

Ouyang ZY, Wang XK and Miao H. A primary study on Chinese terrestrial ecosystem services and their ecological-economic values. Acta Ecologica Sinica 1995;19(5):607-13

Ouyang ZY, Wang XK and Miao H. China's ecoenvironmental sensitivity and its spatial heterogeneity. Acta Ecologica Sinica 2000;20(1):9-12

Shi K, Li Z, Lin F and Zheng R (eds). The Development of China's Forestry: Review and Prospects. The Country Report for Asia-Pacific Forestry Outlook Study. Beijing: China Environmental Sciences Press; 1998

State Environmental Protection Administration of
China (SEPAC) and Editorial Board of Country Research Report for China Biodiversity (EBCRRCB). Country Research Report for China Biodiversity. Beijing: China Environmental Sciences Press; 1998

Sun S and Zhou C. The basic frame for formulating the technical scheme of China national desertification monitoring. In Center for Desertification Monitoring, Bureau of National Forestry, P.R. China (ed.), Study on Desertification Monitoring technology in China. Beijing: China Forestry Publishing; 2000:49-54

The Editorial Board of Forestry in China. Chinese Forest: Vol. 1 Pandect; 1997

United Nations Development Programme (UNDP), United Nations Environment Programme (UNEP), The World Bank, and the World Resources Institute. World Resources 2000-2001 - People and Ecosystems: The fraying web of life. www.wri.org/wr2000

Wiken B, Gauthier, Marshall I et al. (eds). A perspective on Canada's ecosystems. CCEA Occasional Papers No.14; 1996

Wright RG, Murray MP and Merrill T. Ecoregions as a level of ecological analysis. Biological Conservation 1998;86:207-13

Yang QY and Li SC. Some themes on eco-regionalization of China. Acta Ecologica Sinica 1999;19(5): 596-601

Ye XJ, Wang ZQ and Li QS. The ecological agriculture movement in modern China. Agriculture Ecosystems and Environment 2002;92:261-81

Yin R. Forestry and the environment in China: the current situation and strategic choices. World Development 1998;26:2153-67

Zha Yand GaoJ. Characteristics of desertification and its rehabilitation in China. Journal of Arid Environments 1997;37:419-32

Zhong Z. Natural resources planning, management, and sustainable use in China. Resources Policy 1999; 25:211-20

Zhu Z. Current situations and development trends of desertification in Northern China. Journal of Desert Research 1985;5(3):3-11

Zhu Z and Chen G. Land Sandy Desertification in China. Beijing: Science Press; 1994

Zhu $J$ and Zhu Z. Combating Sandy Desertification in China. Beijing: China Forestry Publishing; 1999 